rapid spread of small-pox among the native population in what may be called a virgin soil, "acted promptly" and "appointed lay vaccinators all over the island." The payment of $6 \dot{d}$. a head to the wage-earning class gave a great impetus to the vaccination crusade, so that in the brief period of four months 100,000 people had been vaccinated and the epidemic brought entirely under control. We do well to contrast this result with the efforts of our Local Government Board to parley with the ignorance of the anti-vaccination leaguers. The epidemic which has prevailed for over three years and is now spreading rapidly in the Midlands at a very heavy cost to the rates is the direct result of the pusillanimous action of our executive authorities. What can the proletariat say now in opposition to this perfect method of providing immunity from the deadly effect of small-pox epidemics? The educated classes at least have a claim to protection from the ignorant and even criminal neglect of their poorer neighbours and servants. Is it possible that any of the opponents to vaccination are prompted to take a line directly antagonistic to the expert and scientific conclusions of unbiased investigators because by the decimating effect of uncontrolled epidemic disease populations and families are thereby kept in check? The Times, in its leading article approving of the establishment of the Imperial Vaccination League, says that "small-pox has been shown by a large amount of experience to be in great measure preventable by simple and harmless means."

The disciples of Jenner who can look back to the time when every infant was brought for vaccination as regularly as for baptism and can show the proportionate immunity from the ravages of small-pox pari passu with the spread of effective measures for stamping out the epidemic, have a right to claim national protection from such a fatal and disfiguring disease. Union is strength. It is important, therefore, that our leading statesmen, employers of labour, and those who have the training of the young, should coöperate effectually with the medical men and join the Imperial Vaccination League.

I am, Sirs, yours faithfully,

Jan. 31st, 1903.

Frederick ChuRChILI, F.R.C.S.

\section{MULTIPLE PREGNANCIES.}

\section{To the Editors of THE LANCET.}

StRs,-You may consider the birth of triplets worth recordlng as the mother and children have all thriven. The triplets were born at 36, Prospect-street, Plymouth, in February of last year and are now healthy and strong babies, all girls. The mother also is quite well and the King's bounty was kindly sent to her on my application to the Privy Purse Office through Sir Dighton Probyn. There were three separate placentæ.

I am, Sirs, yours faithfully,

GEORGE BATE, M.R.C.S. Eng.

Plymouth, Jan. 23rd, 1903.

\section{THE NATIONAL HEALTH AND ARMY RECRUITING STATISTICS.}

To the Editors of THE LANCET.

StRs,--I venture to think that the views expressed in the leading article in THE LANCET of Jan. 31st, p. 315, headed "An Impeachment of the National Health," being a consideration of the points brought forward by MajorGeneral Sir F. Maurice in his article in the Contemporary Review entitled "National Health : a Soldier's Study," will commend themselves to the majority of army medical officers having practical experience of army recruiting and the subsequent career of the accepted men when placed under service conditions. Neither medical nor army men will doubt the importance of the question raised, whether as viewed from the larger aspect of the general health or from the more limited sphere of the recruiting grounds, but the subject itself is not a new one. Several years ago Sir T. Orawford published a paper based on army statistics in which he deduced that the physique of the nation was deteriorating - an opinion opposed by the Times in a leading article; and among minor fry who have also contributed to the subject I may range myself, the conclusions being embodied in two communications to one of the leading journals in India in 1890 and being markedly in accord with those advanced in THE LANCET in the article referred to. Yet, whether new or old, its importance to the community is such that any new light which can be thrown upon it, and especially a presentation of it from the military side by one to whom the War Office and the country may listen, cannot but be acceptable; and, moreover, the desirability of ascertaining the true bearing of the facts is apparent.

Now I think it will be granted that no army can properly reflect the national characteristics and conditions unless it be composed of all sections and classes, in amount in proportion to their dominance or otherwise in the general population-an essential which conscription fairly carried out may be said to meet-and that no section in its physical and health aspect can be taken as a true representation of the whole community unless the conditions and circumstances capable of influencing the results are generally present and weigh equally on all the several components. In the case under consideration the question turns on the validity of the conclusions drawn from the data of army recruiting as elucidatory of the national state respecting physique and health. To detail fully all the points which may be advanced against this view would go far beyond the reasonable limits of a letter, but suffice it to suggest the following for consideration. Is it not a fair inference from the statistics that the majority of the volunteers for army service in height, weight, and chest measurement are below the average of our race? and does not a comparison of the recruit as we see him in the streets of the recruiting centres for the line with the passing mass of his fellow-countrymen and the experience of the inspecting medical officers as derived from the ranks of the passed recruits presented to them at the depots or at joining stations at home or abroad fully corroborate this inference from the figures? Do not the occupation columns show that among those presenting themselves in the recruiting offices labourers and servants largely predominate, while mechanics and artisans are few and the middle strata rarely tigure; and are not the localities from which the majority are drawn the large towns and these giving anything but their best-poor material, regard it as we may? Would 1000 of our general population, or even 1000 of the classes and sections represented in the recruiting rooms taken generally give such a large proportion of rejections from inability to comply with the present physical standard or from bodily defects or diseased states (273.75 per 1000 candidates in 1900) as the results for many consecutive years indicate? Surgeon-General Balfour stated that "about two-fifths of the rejections arise from causes connected with general bad health or feeble constitution and among the components of rejection figure defects and diseases attributable to bad and insanitary dwellings and bad feeding producing an impoverished and poor physique and opposing normal bodily development, constitutional debility, and impairment"; but granting that such conditions are too frequently to be met with can they be regarded as characteristic of the country as a whole and as producing such a ratio of defects as the recruit sections demonstrate? The more thought is given to the subject the more does the conclusion strengthen that the limited range of the community from which the recruit is drawn is such as to furnish no adequate basis to work upon on the question of decadence or otherwise of the race and that, to use the words of THE LANCET, "the health statistics of the class desiring to enlist in the army are not those of the population of Great Britain as a whole." What Sir F. Maurice's proportion of wastage-two only out of five effective soldiers at the end of the second year of service-shows is that the present recruiting grounds cannot supply a sufficiency of human material capable of withstanding the pressure of military life. We know well how this poor material succumbs to foreign service conditions and diseasewhat a gap it leaves in the numbers of a regiment required for active service; and the results show that it ought not to be subjected to conditions which it is manifestly unable to bear. It is true that the two of the five who do get beyond two years of military duty-the survival of the fittestdevelop, as a rule, under the fostering influences of good food, good housing, gymnastic exercises, \&c., into excellent army material, but why, in the face of the experience we now have, we should continue to draw from our present restricted and poor stratum only the necessary human basis on which rest in no small degree the prestige and sccurity of our nation is one of those puzzles to which the average intellect cannot furnish a satisfactory answer. Nor is it apparent in what way the 